\title{
A Model To Estimate Synchronous Vibration Amplitude For Detection of Unbalance in Rotor- Bearing System
}

\author{
I. M. Jamadar \\ The National Institute of Engineering, Mysuru, Karnataka, India. E-mail: imranjamadar2@gmail.com.
}

\begin{abstract}
(Received 9 December 2020; accepted 4 March 2021)
A numerical technique for detection of unbalance magnitude of a rotor-bearing system is proposed and verified by experimental analysis. Dimensional analysis is used for development of mathematical model of an unbalanced rotor-bearing system following rigid rotor approach. A developed mathematical model is solved by factorial regression analysis method using the experimental data obtained by a Box-Behnken design. The proposed approach integrates the rotor parameters, disc parameters, bearing parameters and operating conditions with the synchronous vibration amplitude. Confirmation experiments are conducted using Taguchi design methodology with unbalance mass, rotor speed, mass eccentricity and radial load as parameters with different levels assigned to them.
\end{abstract}

\section{INTRODUCTION}

Rotating machines play a vital role in many industries such as manufacturing, cement, food processing, automotive industry etc. to name a few. Failure of the rotating machines severely affects the production rates and the manufacturing cost; hence proper health monitoring and diagnosis of rotating machines is essential. Rotor unbalance is one of the prime contributors to the vibrations in these rotating machines. If unbalance is not corrected, it results into fatigue in support structures, promotes bearing wear, and leads to power loss. Unbalance results in synchronous i.e., $1 \mathrm{x}$ rpm vibration component with a steady amplitude which can be corrected by a technique called dynamic balancing. In the present study only the unbalance fault is taken into consideration synchronous vibration component is taken for unbalance estimation. ${ }^{1}$ Wang et al. ${ }^{2}$ put forth an algorithm that simultaneously identified both the residual unbalance and the dynamic coefficient of the bearing applicable for a single disc and signal span rotor. They modelled the rotor as a homogeneous and continuous Rayleigh beam and then the developed model equation was solved using finite element method. This model is applicable to the rotor supported by both rolling contact bearing as well as the journal bearing. Liu et al. ${ }^{3}$ proposed a method that minimizes the initial unbalance in multistage rotors used in aero engines. They developed a prediction model for initial unbalance of the final multistage rotor assembly and the optimum assembly angle for each rotor. They verified the effectiveness of the proposed method using the balancing machine.

Shrivastava and Mohanty ${ }^{4}$ presented a method for estimation of the unbalance force of rotor-bearing system using a joint-input state estimation technique. The proposed method was experimentally verified for different shaft speeds and noise levels. Sensitivity analysis was also

performed to observe the effect on response by changing system parameters. Ambur and Rinderknecht ${ }^{5}$ proposed the parameter estimation method for the detection of unbalance using frequency domain vibration data. The estimated parameters were the magnitude of unbalance, phase, and location. Al-Shudeifatet al. ${ }^{6}$ studied the unbalance response of the cracked rotor on critical whirl amplitudes using the finite ele- ment method and validated the numerical result by performing experiments. The peak amplitudes corresponding to the critical whirling speeds were found to be significantly altered because of a change in the angle between the unbalance force vector and the crack opening direction. The existence of the angle of the unbalance force vector was found which corresponds to the removal of critical whirl vibration for the cracked rotor system as compared to a crack free rotor. Cao et al. ${ }^{7}$ quantitatively analyzed the effect of fluctuations in the speed on the vibrations of unbalanced rotor. A method based on zoom synchrosqueezing transform (ZST) and tacholess order tracking was proposed for the correction of the unbalance. In the first step, the instantaneous angular speed was obtained using ZST and the corresponding phase was calculated. The signal resampling done to minimize the effect of speed fluctuations. By making use of the discrete Fourier transform, the obtained angular domain signal was then transformed into the order domain to get the amplitude and phase of vibration signal.

Sanches and Pederiva ${ }^{8}$ presented numerical and experimental method for the simultaneous identification of faults such as unbalance and residual shaft bent. Use of the finite element method was made to model the rotor while correlation analysis was used to identify these faults in time domain. The parameters used for the detection were the magnitude of unbalance and the phase for each disc. Developed algorithm was tested for ten cases first without noise and then by adding 6 percent random noise. The predicted fault parameters by the algorithm were satisfactory as compared to their reference experimental values. Shrivastava and Mohanty ${ }^{9}$ proposed a model for estimation of the amplitude and phase of the single plane unbalanced rotor. Kalman filtering and a method based on recursive least square input force estimation was used. The effect of noise, filter parameters, and modelling error on unbalance parameters was analyzed. Use of reduced order model for force estimation makes the analysis fast and highlights its suitability for online monitoring. Wang and Jiang ${ }^{10}$ developed a differential equation for a dual- rotor system with misalignment and unbalance faults. The developed equation was solved using the Runge-Kutta method. T he cascade plot, time waveform, and frequency spectrum were used to identify the faults such as mass eccentricity, misalignment angle and parallel misalign- 
ment. It is observed from the model and experiment that the spectrum of the dual-rotor system consists of the peaks at first two harmonics speed frequency, peak at two times the speed frequency for the misalignment and unbalance.

Yao et al. ${ }^{11}$ proposed two method for the identification of the unbalance parameters. In the first method, use of the modal expansion technique with the optimization algorithm was made while in second, the modal expansion technique was applied to inverse problem. The proposed method is effective for the identification of magnitude and phase of the axial location of the unbalance. Bartkowiak ${ }^{12}$ studied the synchronization of a controlled unbalance rotor. Method of direct separation of motion was used to derive the equations of motion. It is observed that the amplitude of vibration of the supporting body in resonance condition reduces after increasing the unbalance mass. Fonseca et al. ${ }^{13}$ studied the rotor unbalance

and rotor drops in active magnetic bearings. Due to contact of rotor with inner race of back up bearing and the presence of these two phenomena leads to the chaotic motion. They studied the rotor both numerically and experimentally. Their study showed that even a smaller amount of unbalance leads to rotor swing and severely affects its dynamic behavior. Wang et al. ${ }^{14}$ put forth a mathematical model for identification of the unbalance of the single-span single -disc rotor in that the rotor was modeled as elastic Euler-Bernoulli beam and the forces exerted by bearings and the disc on the rotor were considered as point forces. Their proposed method turned out to be efficient for rotor balancing without a test run and external excitation. Shamsah et al. ${ }^{15}$ put forth a novel method for the detection of rotor unbalance with a technique involving a lesser number of sensors. The method can be beneficial for the bigger rotating machineries having number of bearings. With the reduced number of sensors, the computational time required for the signal processing will be significantly reduced and ultimately the machinery downtime could also be reduced. Yadav et al. ${ }^{16}$ studied the effect of unbalance forces on the dynamics of high-speed rotors having ball bearing of radial clearance as a non-linearity. The dynamic response was studied using Poincare maps, orbit plots and power spectra. Ocampo et al. ${ }^{17}$ proposed the polar plot analysis method for the identification of the angular position of the unbalance force on nonsymmetric rotors. They developed a two degree of freedom mathematical model of a rotor with an unequal principal moment of inertia of the shaft in transverse direction. Bartkowiak et al. ${ }^{18}$ studied the synchronization of the unbalanced rotor for forced excitation condition. Numerically, it was seen that, for the system in resonance, the control law can control the synchronization at its existence limit. Also, the amplitude of vibration of supporting body in resonance condition can be minimized by increasing the unbalance mass while the energy of excitation further transferred to rotor. Wen et al. ${ }^{19}$ developed a dynamic model of rotor system with four degrees of freedom to determine the reaction forces due to rotor unbalance. Based on these reaction forces, a three degree of freedom dynamic model of bearing cage motion was also proposed. Experimental validation of the simulation result was carried out and the presence of cage rotating frequency, its multiple harmonics, inner race rotation frequency, combined frequencies were observed due to presence of unbalance. M. Arias-Montiel et al. ${ }^{20}$ presented methodology for the unbalance control of the asymmetrical two disk rotor-bearing system. They used the finite element method for mathematical modelling. The methodology was based on the asymptotic state observer using displacement measurement at both disks.

The present work aims to estimate the synchronous vibration amplitude so at to detect the presence of the unbalance in rotor bearing system. The method integrates the unbalance magnitude with vibration amplitude by considering the rotor parameters, disc parameters, bearing parameters and operating conditions so that with capturing of the vibration signal in frequency domain it is possible to detect the presence as well as the magnitude of unbalance in rotating machines of practical interest. All these parameters together considered first time in the mathematical modelling for rotor unbalance detection and adds novel contribution to this field. Developed mathematical model equation is solved by factorial regression analysis method using the experimental data obtained by BoxBehnken design. The validation experimentation is conducted using Taguchi design methodology with unbalance mass, rotor speed, mass eccentricity and radial load on rotor as parameters with different levels assigned to them.

\section{FORMULATION OF MATHEMATICAL MODEL}

A mathematical model was derived here for defining the correlation between vibration response and the unbalance on the rotor-bearing system. Dimensional analysis ${ }^{21-23}$ was used for development of theoretical model equations. It was assumed that the synchronous vibration displacement response due to presence of rotor unbalance depends on the parameters given in Eq. (1).

$$
\begin{aligned}
\text { Synchronous amplitude }= & f\left(d_{s}, \rho_{s}, L_{s}, m_{s}, E_{s}, \mathrm{di}_{\text {Disc }},\right. \\
& \operatorname{do}_{\text {Disc }}, e_{r}, t_{\text {Disc }}, \mathbf{M}_{\text {Disc }}, E_{\text {Disc }}, \\
& \rho_{\text {Disc }}, K_{c}, k, \delta, C, \nu, c_{r}, D_{i}, D_{o}, \\
& \left.D_{r}, D_{p}, Z, W_{r}, M_{u}, N\right) .
\end{aligned}
$$

The following procedure was adopted for obtaining the dimensionless parameters for vibration response of unbalanced rotor.

i. Determination of the parameters as in Eq. (1) and expressing their dimensions in Mass (M), length (L) and Time (T) system of units as in Tab. 1.

ii. Selection of the repeating parameters from the parameters listed in Eq. (1). Here, the rotor diameter $\left(R_{1}=d_{s}\right)$, rotor speed $\left(R_{2}=N\right)$ and radial load on the rotor $\left(R_{3}=W_{r}\right)$ were selected as repeating parameters.

iii. Expressing the matrix of the repeating parameters as,

$$
[R]=\left[\begin{array}{lll}
R_{11} & R_{12} & R_{13} \\
R_{21} & R_{22} & R_{23} \\
R_{31} & R_{32} & R_{33}
\end{array}\right] \begin{gathered}
M \\
L
\end{gathered} .
$$

Here the number of fundamental dimensions in Tab. 1 are 3, hence the number of repeating variables (r) chosen are 3 .

i. The parameters other than repeating are the non-repeating parameters. Writing the matrix of the non-repeating parameters as,

$$
[U]=\left[\begin{array}{ccccc}
U_{11} & U_{12} & . & . & U_{1 n} \\
U_{21} & U_{22} & . & . & U_{2 n} \\
U_{31} & U_{32} & . & . & U_{3 n}
\end{array}\right] \begin{gathered}
M \\
L \\
T
\end{gathered}
$$




\begin{tabular}{|c|c|c|c|}
\hline Parameter & Symbol & Unit & Dimension \\
\hline \multicolumn{4}{|c|}{ Rotor Parameters } \\
\hline Rotor diameter & $d_{s}$ & $\mathrm{~mm}$ & $\mathrm{~L}$ \\
\hline Mass density of rotor & $\rho_{s}$ & $\mathrm{Kg} / \mathrm{m}^{3}$ & $\mathrm{ML}^{-3}$ \\
\hline Rotor length & $\mathrm{L}_{\mathrm{s}}$ & $\mathrm{mm}$ & $\mathrm{L}$ \\
\hline Mass of rotor & $\mathrm{m}_{\mathrm{s}}$ & $\mathrm{Kg}$ & M \\
\hline Elastic modulus of rotor & $\mathrm{E}_{\mathrm{s}}$ & $\mathrm{N} / \mathrm{m}^{2}$ & $\mathrm{ML}^{-1} \mathrm{~T}^{-2}$ \\
\hline \multicolumn{4}{|c|}{ Disc Parameters } \\
\hline Inner diameter of disc & $\mathrm{di}_{\text {Disc }}$ & $\mathrm{mm}$ & $\mathrm{L}$ \\
\hline Outer diameter of disc & do $_{\text {Disc }}$ & $\mathrm{mm}$ & $\mathrm{L}$ \\
\hline Eccentricity radius & $\mathrm{e}_{\mathrm{r}}$ & $\mathrm{mm}$ & $\mathrm{L}$ \\
\hline Disc thickness & $t_{\text {Disc }}$ & $\mathrm{mm}$ & $\mathrm{L}$ \\
\hline Mass of Disc & $\mathrm{M}_{\text {Disc }}$ & $\mathrm{Kg}$ & $\mathrm{M}$ \\
\hline Elastic modulus of disc & $\mathrm{E}_{\text {Disc }}$ & $\mathrm{N} / \mathrm{m}^{2}$ & $\mathrm{ML}^{-1} \mathrm{~T}^{-2}$ \\
\hline Mass of density of disc & $\rho_{\text {Disc }}$ & $\mathrm{Kg} / \mathrm{m}^{3}$ & $\mathrm{ML}^{-3}$ \\
\hline \multicolumn{4}{|c|}{ Bearing Parameters } \\
\hline Constant for contact deformation & $\mathrm{K}_{\mathrm{c}}$ & $\mathrm{N} / \mathrm{mm}^{1.5}$ & $\mathrm{ML}^{-0.5} \mathrm{~T}^{-2}$ \\
\hline Curvature ratio & $\mathrm{k}$ & -- & -- \\
\hline Deflection & $\delta$ & $\mathrm{Mm}$ & $\mathrm{L}$ \\
\hline Damping coefficient & $\mathrm{C}$ & $\mathrm{Ns} / \mathrm{m}$ & $\mathrm{MT}^{-3}$ \\
\hline Lubricant viscosity & $\nu$ & $\mathrm{mm}^{2} / \mathrm{s}$ & $\mathrm{L}^{2} \mathrm{~T}^{-1}$ \\
\hline Radial clearance & $\mathrm{C}_{\mathrm{r}}$ & $\mathrm{mm}$ & $\mathrm{L}$ \\
\hline Inner race diameter & $\mathrm{D}_{\mathrm{i}}$ & $\mathrm{mm}$ & $\mathrm{L}$ \\
\hline Outer race diameter & $\mathrm{D}_{\mathrm{o}}$ & $\mathrm{mm}$ & $\mathrm{L}$ \\
\hline Roller diameter & $D_{r}$ & $\mathrm{~mm}$ & $\mathrm{~L}$ \\
\hline Pitch diameter & $\mathrm{D}_{\mathrm{p}}$ & $\mathrm{mm}$ & $\mathrm{L}$ \\
\hline Number of rollers & $\mathrm{Z}$ & -- & -- \\
\hline \multicolumn{4}{|c|}{ Operating Parameters } \\
\hline Radial load & $\mathrm{W}_{\mathrm{r}}$ & $\mathrm{N}$ & MLT $^{-2}$ \\
\hline Unbalance & $\mathrm{M}_{\mathrm{u}}$ & gm & M \\
\hline Speed & $\mathrm{N}$ & $\mathrm{rpm}$ & $\mathrm{T}^{-1}$ \\
\hline \multicolumn{4}{|c|}{ Response Parameters } \\
\hline Displacement & $\mathrm{y}$ & $\mu \mathrm{m}$ & $\mathrm{L}$ \\
\hline
\end{tabular}

ii. Deciding the number of dimensionless parameters. The total number of parameters (n) including the response as listed in Eq. (1) were 27. The number of repeating parameters selected were 3 . Hence, the number of dimensionless parameters were 25 (n-r).

iii. Applying the matrix method ${ }^{22}$ for obtaining the nondimensionless parameters as,

$$
\frac{U_{n}}{R_{1}^{C_{1 n}} R_{2}^{C_{2 n}} R_{3}^{C_{3 n}}}=M^{0} L^{0} T^{0}=\left(\pi_{n}\right) .
$$

iv. Substitution of dimensions of parameters from Eqs. (2) and (3) in Eq. (4) as,

$$
\frac{\left(M^{U_{1 n}} L^{U_{2 n}} T^{U_{3 n}}\right)}{\left[\begin{array}{c}
\left(M^{R_{11}} L^{R_{21}} T^{R_{31}}\right)^{C_{1 n}} \cdot\left(M^{R_{12}} L^{R_{22}} T^{R_{32}}\right)^{C_{2 n}} \\
\cdot\left(M^{R_{13}} L^{R_{23}} T^{R_{33}}\right)^{C_{3 n}}
\end{array}\right]}=\left(\pi_{n}\right) .
$$

v. Expressing Eq. (5) as algebraic equation,

$$
\begin{aligned}
& R_{11} C_{1 n}+R_{12} C_{2 n}+R_{13} C_{3 n}=U_{1 n} ; \\
& R_{21} C_{1 n}+R_{22} C_{2 n}+R_{23} C_{3 n}=U_{2 n} ; \\
& R_{31} C_{1 n}+R_{32} C_{2 n}+R_{33} C_{3 n}=U_{3 n} .
\end{aligned}
$$

vi. Solving the simultaneous Eq. (6) to obtain the dimensionless parameters as listed in Tab. 2.
Table 2. Parameters in Non-dimensional form.

\begin{tabular}{||l|l|l|l||}
\hline$\pi_{\rho s}$ & $\frac{\rho_{s} d_{s}{ }^{4} N^{2}}{W_{r}}$ & $\pi_{k}$ & $k$ \\
$\pi_{L_{s}}$ & $\frac{L_{s}}{d_{s}}$ & $\pi_{\delta}$ & $\frac{\delta}{d_{s}}$ \\
$\pi_{m_{s}}$ & $\frac{m_{s} d_{s} N^{2}}{W_{r}}$ & $\pi_{C}$ & $\frac{C d_{s}}{N W_{r}}$ \\
$\pi_{E_{s}}$ & $\frac{E_{s} d_{s}^{2}}{W_{r}}$ & $\pi_{v}$ & $\frac{\nu}{d_{s}^{2} N}$ \\
$\pi_{d i_{D i s c}}$ & $\frac{d i_{D i s c}}{d_{s}}$ & $\pi_{c_{r}}$ & $\frac{c_{r}}{d_{s}}$ \\
$\pi_{d o_{D i s c}}$ & $\frac{d o_{D i s c}}{d_{s}}$ & $\pi_{D_{i}}$ & $\frac{D_{i}}{d_{s}}$ \\
$\pi_{e_{r}}$ & $\frac{e_{r}}{d_{s}}$ & $\pi_{D_{o}}$ & $\frac{D_{o}}{d_{s}}$ \\
$\pi_{t_{D i s c}}$ & $\frac{t_{D i s c}}{d_{s}}$ & $\pi_{D_{r}}$ & $\frac{D_{r}}{d_{s}}$ \\
$\pi_{M_{D i s c}}$ & $\frac{M_{D i s c} d_{s} N^{2}}{W_{r}}$ & $\pi_{D_{p}}$ & $\frac{D_{p}}{d_{s}}$ \\
$\pi_{E_{D i s c}}$ & $\frac{E_{D i s c} d_{s}^{2}}{W_{r}}$ & $\pi_{Z}$ & $Z$ \\
$\pi_{\rho_{D i s c}}$ & $\frac{\rho_{D i s c} d_{s} N^{2}}{W_{r}}$ & $\pi_{M_{u}}$ & $\frac{M_{u} d_{s} N^{2}}{W_{r}}$ \\
$\pi_{K_{c}}$ & $\frac{K_{c} d_{s}}{W_{r}}$ & $\pi_{y}$ & $\frac{y}{d_{s}}$ \\
\hline
\end{tabular}

vii. Substitution of dimensionless parameter from Tab. 2 in Eq. (1).

$$
\begin{aligned}
\frac{y}{d_{s}}= & f\left(\frac{\rho_{s} d_{s}{ }^{4} N^{2}}{W_{r}}, \frac{L_{s}}{d_{s}}, \frac{m_{s} d_{s} N^{2}}{W_{r}}, \frac{E_{s} d_{s}{ }^{2}}{W_{r}}, \frac{\mathrm{di}_{\text {Disc }}}{d_{s}}, \frac{\mathrm{do}_{\text {Disc }}}{d_{s}},\right. \\
& \frac{e_{r}}{d_{s}}, \frac{t_{\text {Disc }}}{d_{s}}, \frac{M_{\text {Disc }} d_{s} N^{2}}{W_{r}}, \frac{E_{\text {Disc }} d_{s}{ }^{2}}{W_{r}}, \frac{\rho_{\text {Disc }} d_{s}{ }^{4} N^{2}}{W_{r}} \\
& \frac{K_{c} d_{s}{ }^{1.5}}{W_{r}}, k, \frac{\delta}{d_{s}}, \frac{C d_{s}}{\mathrm{NW}_{r}}, \frac{c_{r}}{d_{s}{ }^{2} \mathrm{~N}}, \frac{D_{i}}{d_{s}}, \frac{D_{o}}{d_{s}}, \frac{D_{r}}{d_{s}} \\
& \left.\frac{D_{p}}{d_{s}}, Z, \frac{M_{u} d_{s} N^{2}}{W_{r}}\right) .
\end{aligned}
$$

Equation (7) represented the theoretical model for defining the vibration displacement due to unbalance. In Eq. (7) the function ' $f$ ' is to be obtained experimentally.

\section{REDUCED ORDER MODELLING}

Now, as the parameters in Eq. (7) were still more, the computational time required to solve these equations was more. Hence, it was required to reduce the number of parameters. This was done by performing the mathematical operations in dimensional analysis as, ${ }^{24}$

i.

$$
\pi_{1}=\frac{\pi_{\mathrm{s}}}{\pi_{E_{s}}} \times \pi_{L_{s}}=\frac{\rho_{s} \times d_{s} \times N^{2} \times L_{s}}{E_{s}} ;
$$

ii.

$$
\pi_{2}=\pi_{m_{s}} \times \pi_{e_{r}}=\frac{m_{s} \times N^{2} \times e_{r}}{W_{r}}
$$

iii.

$$
\pi_{3}=\frac{\pi_{M_{\text {Disc }}} \times \pi_{\rho_{\text {Disc }}}}{\pi_{E_{\text {Disc }}}}=\frac{M_{\text {Disc }} \times d_{s}{ }^{3} \times N^{4} \times \rho_{\text {Disc }}}{E_{\text {Disc }} \times W_{r}} ;
$$

iv.

$$
\pi_{4}=\frac{\pi_{C_{r}} \times \pi_{D_{p}}}{\pi_{D_{r}} \times \pi_{v} \times \pi_{Z} \times \pi_{K_{c}}}=\frac{N \times C_{r} \times D_{p} \times W_{r}}{d_{s}{ }^{0.5} \times v \times D_{r} \times Z \times K_{c}} ;
$$

V.

$$
\pi_{5}=\pi_{M_{u}}=\frac{M_{u} d_{s} N^{2}}{W_{r}}
$$

vi.

$$
\theta=\pi_{\mathrm{di}_{\text {Disc }}} \times \pi_{\mathrm{do}_{\text {Disc }}} \times \pi_{t_{\text {Disc }}} \times \pi_{C} \times \pi_{D_{i}} \times \pi_{D_{O}} \times \pi_{k} \times \pi_{\delta} .
$$


Substituting the Eqs. (8) to (13) in Eq. (7) we get,

$$
\begin{aligned}
\frac{y}{d_{s}}= & \left(\theta, \frac{\rho_{s} \times d_{s} \times N^{2} \times L_{s}}{E_{s}}, \frac{m_{s} \times N^{2} \times e_{r}}{W_{r}}\right. \\
& \frac{M_{\text {Disc }} \times d_{s}{ }^{3} \times N^{4} \times \rho_{\text {Disc }}}{E_{\text {Disc }} \times W_{r}}, \frac{N \times C_{r} \times D_{p} \times W_{r}}{d_{s}{ }^{0.5} \times v \times D_{r} \times Z \times K_{c}}, \\
& \left.\frac{M_{u} d_{s} N^{2}}{W_{r}}\right) .
\end{aligned}
$$

Equation (14) represents the reduced order model of the original model given in Eq. (7) wherein the number of parameters was reduced from 23 to 6 without affecting the physics of the problem. To solve the Eq. (14), and for evaluating the function ' $f$ ', the use of design of experiments with multivariable regression technique was used. ${ }^{23-25}$ Expressing the Eq. (14) in the form of power law,

$$
\frac{y}{d_{s}}=\theta \times\left(\pi_{1}\right)^{p} \times\left(\pi_{2}\right)^{q} \times\left(\pi_{3}\right)^{r} \times\left(\pi_{4}\right)^{s} \times\left(\pi_{5}\right)^{t} ;
$$

where, 'p' to 't' were the unknowns which were to be evaluated experimentally. For further simplification, taking log on the both the sides of Eq. (15) we get,

$$
\begin{aligned}
\log \left(\frac{y}{d_{s}}\right)= & \log \theta+p \times \log \left(\pi_{1}\right)+q \times \log \left(\pi_{2}\right)+r \times \log \left(\pi_{3}\right) \\
& +s \times \log \left(\pi_{4}\right)+t \times \log \left(\pi_{5}\right)
\end{aligned}
$$

Now, let us assume that,

$$
\begin{array}{llrl}
\log \left(\frac{y}{d_{s}}\right) & =Y ; & & \log (\theta)=a_{0} ; \\
\log \left(\pi_{1}\right)=x_{1} ; & & \log \left(\pi_{2}\right)=x_{2} ; \\
\log \left(\pi_{3}\right)=x_{3} ; & & \log \left(\pi_{4}\right)=x_{4} ; \\
\log \left(\pi_{5}\right)=x_{5} . &
\end{array}
$$

Hence, Eq. (20) became,

$$
Y=a_{0}+p x_{1}+q x_{2}+r x_{3}+s x_{4}+t x_{5}
$$

Now, to evaluate the unknowns in Eq. (17), if ' $n$ ' experiments were performed then the results of all experiments can be summed as,

$$
\begin{aligned}
\sum_{j=1}^{n} Y_{i}= & n a_{0}+p \sum_{j=1}^{n} x_{j 1}+q \sum_{j=1}^{n} x_{j 2}+r \sum_{j=1}^{n} x_{j 3} \\
& +s \sum_{j=1}^{n} x_{j 4}+t \sum_{j=1}^{n} x_{j 5}
\end{aligned}
$$

where, the suffix ' $j$ ' in above equation represented the $j^{\text {th }}$ experiment. As there were six unknowns in Eq. (17), it was required to develop six simultaneous equations which were developed and written in matrix form given in Eq. (19) and is solved using a MATLAB coding. ${ }^{26}$

$$
\begin{aligned}
& {\left[\begin{array}{ccc}
n & \sum_{j=1}^{n} x_{j 1} & \sum_{j=1}^{n} x_{j 2} \\
\sum_{j=1}^{n} x_{j 1} & \sum_{j=1}^{n} x_{j 1} x_{j 1} & \sum_{j=1}^{n} x_{j 1} x_{j 2} \\
\sum_{j=1}^{n} x_{j 2} & \sum_{j=1}^{n} x_{j 2} x_{j 1} & \sum_{j=1}^{n} x_{j 2} x_{j 2} \\
\sum_{j=1}^{n} x_{j 3} & \sum_{j=1}^{n} x_{j 3} x_{j 1} & \sum_{j=1}^{n} x_{j 3} x_{j 2} \\
\sum_{j=1}^{n} x_{j 4} & \sum_{j=1}^{n} x_{j 4} x_{j 1} & \sum_{j=1}^{n} x_{j 4} x_{j 2} \\
\sum_{j=1}^{n} x_{j 5} & \sum_{j=1}^{n} x_{j 5} x_{j 1} & \sum_{j=1}^{n} x_{j 5} x_{j 2}
\end{array} \ldots\right.} \\
& \left.\begin{array}{rcc}
\sum_{j=1}^{n} x_{j 3} & \sum_{j=1}^{n} x_{j 4} & \sum_{j=1}^{n} x_{j 5} \\
\sum_{j=1}^{n} x_{j 1} x_{j 3} & \sum_{j=1}^{n} x_{j 1} x_{j 4} & \sum_{j=1}^{n} x_{j 1} x_{j 5} \\
\sum_{j=1}^{n} x_{j 2} x_{j 3} & \sum_{j=1}^{n} x_{j 2} x_{j 4} & \sum_{j=1}^{n} x_{j 2} x_{j 5} \\
\sum_{j=1}^{n} x_{j 3} x_{j 3} & \sum_{j=1}^{n} x_{j 3} x_{j 4} & \sum_{j=1}^{n} x_{j 3} x_{j 5} \\
\sum_{j=1}^{n} x_{j 4} x_{j 3} & \sum_{j=1}^{n} x_{j 4} x_{j 4} & \sum_{j=1}^{n} x_{j 4} x_{j 5} \\
\sum_{j=1}^{n} x_{j 5} x_{j 3} & \sum_{j=1}^{n} x_{j 5} x_{j 4} & \sum_{j=1}^{n} x_{j 5} x_{j 5}
\end{array}\right]\left[\begin{array}{c}
a_{0} \\
p \\
q \\
r \\
s \\
t
\end{array}\right] \\
& =\left[\begin{array}{c}
\sum_{j=1}^{n} Y_{i} \\
\sum_{j=1}^{n} x_{j 1} Y_{j} \\
\sum_{j=1}^{n} x_{j 2} Y_{j} \\
\sum_{j=1}^{n} x_{j 3} Y_{j} \\
\sum_{j=1}^{n} x_{j 4} Y_{j} \\
\sum_{j=1}^{n} x_{j 5} Y_{j}
\end{array}\right] .
\end{aligned}
$$

\section{EXPERIMENTATION AND DATA ACQUISITION}

Now, to obtain the unknowns in model equation (15) and to execute the Box-Behnken design [BBD] for obtaining the experimental data to get solution to the matrix equation (19), a design matrix was obtained using the MINITAB software that has dimensions of the $[(2 f(f-1)+C p f)]$ for experimental runs in that $\boldsymbol{f}$ indicated the number of factors and $\boldsymbol{C p}$ indicated the number of central points. Accordingly, in the analysis of the vibration response of the unbalanced rotor due to factors such as mass unbalance, rotor speed, mass eccentricity and radial load on rotor, different combinations of these factors were executed to verify the dependence of the vibration amplitude at synchronous frequency component on these factors giving total 27 experimental data sets. Figure 1 (a) shows the actual experimental setup, 1 (b) shows the schematic of the system and Fig. 1 (c) shows the data acquisition system, accelerometers used for conducting the experiments. Experimental setup consisted of a rotor-shaft driven by a $1.5 \mathrm{~kW}$ DC motor. The speed regulation was achieved by dimmer switch. The shaft was coupled to a motor through a flexible coupling and was supported by SKF 6005 ball bearings at both ends and lubricated by SKF LGHP2 grease having base Oil viscosity at $40^{\circ} \mathrm{C}, 96 \mathrm{~mm}^{2} / \mathrm{s}$. A hydraulic loading arrangement was used to provide the radial load and rotor unbalance is created by placing masses of different magnitude and radii on a balance disc as shown in Fig. 1 (a-b).

A piezoelectric accelerometer as shown in Fig. 1 (c) (AdashAC102-1A) was mounted on the housing of the support bearing that captures the vibration signature of the unbalanced rotor. The signals were sampled with a sampling frequency of $4096\left(2^{12}\right) \mathrm{Hz}$. The digital tachometer of non-contacting type gave the direct speed measurement. Table 3 shows factors and their levels used for carrying out the experiments.

\section{RESPONSE SURFACE METHOD [RSM]}

The RSM involves collection and mathematical analysis of the experimental data using statistical techniques. The RSM 
Table 3. Factors and levels for experimental runs.

\begin{tabular}{|l|l|l|l|}
\hline \multirow{2}{*}{ Factors } & \multicolumn{3}{|c|}{ Levels } \\
\cline { 2 - 4 } & $\mathbf{L}_{1}$ & $\mathbf{L}_{2}$ & $\mathbf{L}_{3}$ \\
\hline $\mathbf{M}_{\mathbf{u}}$ & 15 & 20 & 25 \\
$\mathbf{N}$ & 1020 & 2040 & 3060 \\
$\mathbf{e}_{\mathbf{r}}$ & 60 & 70 & 80 \\
$\mathbf{W}_{\mathbf{r}}$ & 1000 & 2000 & 3000 \\
\hline
\end{tabular}

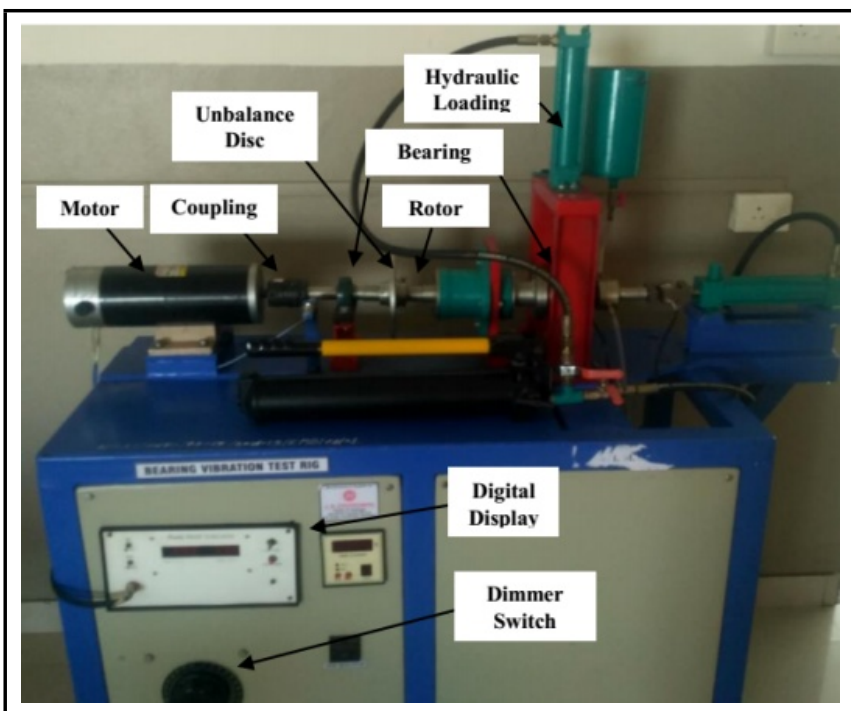

(a)

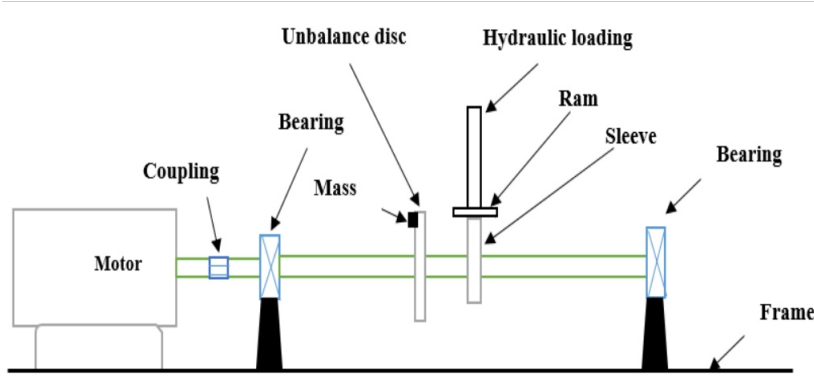

(b)

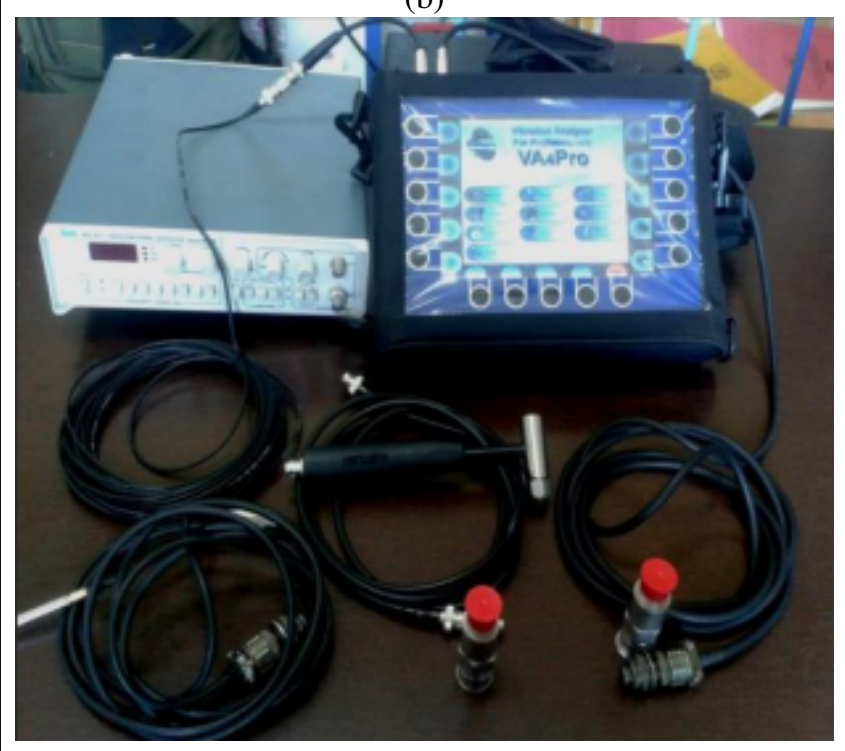

(c)

Figure 1. (a) Experimental setup photograph, (b) Schematic of test rig (b) Data acquisition system.
Table 4. Experiment Design Matrix and Result.

\begin{tabular}{|c|c|c|c|c|c|}
\hline Run Order & $\mathrm{M}_{\mathrm{u}}$ & $\mathrm{N}$ & $e_{r}$ & W & $\mathrm{Y}$ \\
\hline 1 & 15 & 2040 & 60 & 2000 & 25.19 \\
\hline 2 & 20 & 2040 & 80 & 1000 & 49.66 \\
\hline 3 & 15 & 3060 & 70 & 2000 & 43.45 \\
\hline 4 & 15 & 2040 & 70 & 1000 & 28.72 \\
\hline 5 & 25 & 2040 & 80 & 2000 & 75.78 \\
\hline 6 & 20 & 1020 & 80 & 2000 & 53.88 \\
\hline 7 & 20 & 2040 & 60 & 1000 & 22.57 \\
\hline 8 & 20 & 3060 & 60 & 2000 & 34.14 \\
\hline 9 & 20 & 3060 & 70 & 1000 & 38.94 \\
\hline 10 & 15 & 1020 & 70 & 2000 & 31.16 \\
\hline 11 & 20 & 1020 & 60 & 2000 & 24.49 \\
\hline 12 & 20 & 2040 & 70 & 2000 & 46.08 \\
\hline 13 & 20 & 2040 & 70 & 2000 & 46.08 \\
\hline 14 & 20 & 3060 & 80 & 2000 & 75.12 \\
\hline 15 & 20 & 1020 & 70 & 1000 & 27.92 \\
\hline 16 & 25 & 2040 & 60 & 2000 & 34.77 \\
\hline 17 & 20 & 1020 & 70 & 3000 & 44.30 \\
\hline 18 & 25 & 2040 & 70 & 3000 & 62.90 \\
\hline 19 & 20 & 2040 & 80 & 3000 & 78.79 \\
\hline 20 & 20 & 2040 & 60 & 3000 & 35.81 \\
\hline 21 & 20 & 2040 & 70 & 2000 & 46.08 \\
\hline 22 & 15 & 2040 & 80 & 2000 & 55.42 \\
\hline 23 & 25 & 3060 & 70 & 2000 & 59.97 \\
\hline 24 & 25 & 1020 & 70 & 2000 & 43.01 \\
\hline 25 & 20 & 3060 & 70 & 3000 & 61.77 \\
\hline 26 & 15 & 2040 & 70 & 3000 & 45.57 \\
\hline 27 & 25 & 2040 & 70 & 1000 & 39.65 \\
\hline
\end{tabular}

was suitable for the modeling and analysis of a physical problem wherein an output or response variable was influenced by several factors and it was also desired to optimize the response variable. BBD was the important class of the three level designs for fitting the second order response in RSM. ${ }^{27}$ In this work BBD was used for assembling second order polynomial equation and for exploring the quadratic response surface. This design consisted of three replicated points at the center of a multidimensional cube and a set of points in the middle of each side. The multinomial equation (20) was derived using Minitab software.

$$
\begin{aligned}
y_{i}= & \beta_{0}+\beta_{1} M_{u_{i}}+\beta_{2} N+\beta_{3} e_{r}+\beta_{4} W_{r}+\beta_{5} M_{u} M_{u} \\
& +\beta_{6} \mathrm{NN}+\beta_{7} e_{r} e_{r}+\beta_{8} W_{r} W_{r}+\beta_{9} M_{u} N+\beta_{10} M_{u} e_{r} \\
& +\beta_{11} M_{u} W_{r}+\beta_{12} N e_{r}+\beta_{13} N W_{r}+\beta_{14} e_{r} W_{r}+e_{i} ;
\end{aligned}
$$

where, $\beta_{0}$ indicated intercept and $\beta_{1}$ to $\beta_{14}$ were the regression coefficients. The terms $e_{i}$ represented the experimental error and the subscript ' $i$ ' indicated the experiment number.

\section{RESULTS AND DISCUSSIONS}

In the present study, an experimental setup as shown in Fig. 1 is used to analyze the effect of different factors on the vibration displacement amplitude at synchronous frequency of an unbalanced rotor. Table 4 shows the design matrix obtained using MINITAB software and in that the last column of the matrix shows the response variable which is vibration displacement amplitude obtained using the vibration analyzer.

For the solution of the constants of Eq. (19), the data set of Table 4 is used which yields,

$$
\begin{aligned}
& a_{0}=-3.2295 ; \quad p=-2.5098 ; \quad q=2.7395 ; \\
& r=-1.0379 ; \quad s=2.7459 ; \quad t=0.6280 .
\end{aligned}
$$




\begin{tabular}{|c|c|c|c|c|c|c|}
\hline Source & DF & Coefficient & SS & MS & $F$ & P \\
\hline Model & 14 & +144.6 & 6487.82 & 463.42 & 2651.59 & 0.000 \\
\hline Linear & 4 & - & 6269.17 & 1567.29 & 8967.79 & 0.000 \\
\hline $\mathrm{M}_{\mathrm{u}}$ & 1 & -2.784 & 624.25 & 624.25 & 3571.87 & 0.000 \\
\hline $\mathrm{N}$ & 1 & -0.01571 & 664.04 & 664.04 & 3799.50 & 0.000 \\
\hline$e_{r}$ & 1 & -3.620 & 3734.34 & 3734.34 & 21367.25 & 0.000 \\
\hline $\mathrm{W}_{\mathrm{r}}$ & 1 & -0.02175 & 1246.55 & 1246.55 & 7132.53 & 0.000 \\
\hline Square & 4 & - & 64.63 & 16.16 & 92.45 & 0.000 \\
\hline $\mathrm{M}_{\mathrm{u}} * \mathrm{M}_{\mathrm{u}}$ & 1 & -0.01637 & 0.89 & 0.89 & 5.11 & 0.043 \\
\hline $\mathrm{N} * \mathrm{~N}$ & 1 & -0.000001 & 8.47 & 8.47 & 48.44 & 0.000 \\
\hline$e_{r} * e_{r}$ & 1 & +0.02094 & 23.39 & 23.39 & 133.84 & 0.000 \\
\hline $\mathrm{W}_{\mathrm{r}} * \mathrm{~W}_{\mathrm{r}}$ & 1 & -0.000001 & 11.28 & 11.28 & 64.52 & 0.000 \\
\hline Interaction & 6 & - & 154.03 & 25.67 & 146.88 & 0.000 \\
\hline $\mathrm{M}_{\mathrm{u}} * \mathrm{~N}$ & 1 & 0.000299 & 5.46 & 5.46 & 31.23 & 0.000 \\
\hline $\mathrm{M}_{\mathrm{u}} * \mathrm{e}_{\mathrm{r}}$ & 1 & 0.05391 & 29.06 & 29.06 & 166.27 & 0.000 \\
\hline $\mathrm{M}_{\mathrm{u}} * \mathrm{~W}_{\mathrm{r}}$ & 1 & 0.000320 & 10.26 & 10.26 & 58.69 & 0.000 \\
\hline $\mathrm{N}^{*} \mathrm{e}_{\mathrm{r}}$ & 1 & 0.000284 & 33.58 & 33.58 & 192.16 & 0.000 \\
\hline $\mathrm{N}^{*} \mathrm{~W}_{\mathrm{r}}$ & 1 & 0.000002 & 12.55 & 12.55 & 71.84 & 0.000 \\
\hline $\mathrm{e}_{\mathrm{r}} * \mathrm{~W}_{\mathrm{r}}$ & 1 & 0.000397 & 63.11 & 63.11 & 361.13 & 0.000 \\
\hline Error & 12 & - & 2.10 & 0.17 & - & - \\
\hline Lack of Fit & 10 & - & 2.10 & 0.21 & - & - \\
\hline Pure Error & 2 & - & 0.00 & 0.00 & - & - \\
\hline Total & 26 & - & 6489.92 & - & - & - \\
\hline \multicolumn{7}{|c|}{$\mathrm{R}^{2}=99.97 \% \quad \mathrm{R}^{2}-(\mathrm{adj})=99.81 \%$} \\
\hline
\end{tabular}

Hence the model Eq. (15) becomes,

$$
\begin{aligned}
\frac{y}{d_{s}}= & 0.0395 \times\left(\pi_{1}\right)^{-2.5098} \times\left(\pi_{2}\right)^{2.7395} \times\left(\pi_{3}\right)^{-1.0379} \\
& \times\left(\pi_{4}\right)^{2.7459} \times\left(\pi_{5}\right)^{0.6280}
\end{aligned}
$$

\subsection{Analysis of Variance [ANOVA]}

ANOVA Table summarizes main effects, factor interactions, and $\mathrm{P}$-value. The $\mathrm{P}$-value is an important indicator stating the significance of a factor. P-values are frequently used in hypothesis testing for accepting or rejecting a null hypothesis. As P-values is smaller, it is an indication of significance of a factor and a cut off value of 0.05 is used for accepting or rejecting the null hypothesis. ${ }^{27}$ Table 7 shows the results of the ANOVA on experimental data.

By making use of the design of experiments, the coefficients of the multinomial Eq. (20) are obtained as,

$$
\begin{aligned}
y_{i}= & 144.6-2.784 M_{u_{i}}-0.01571 N-3.620 e_{r} \\
& -0.02175 W_{r}-0.01637 M_{u} M_{u}-0.000001 \mathrm{NN} \\
& +0.02094 e_{r} e_{r}-0.000001 W_{r} W_{r}+0.000229 M_{u} N \\
& +0.05391 M_{u} e_{r}+0.000320 M_{u} W_{r}+0.000284 N e_{r} \\
& +0.000002 N W_{r}+0.000397 e_{r} W_{r} .
\end{aligned}
$$

Equation (22) is used for prediction of the radial vibration displacement amplitude of the synchronous frequency component due to unbalance. To substantiate, the determined polynomials are significant or not, variance analysis and an F- ratio test was performed on them. The F-value obtained for the model is 2651.59 which show that the model is significant.

\subsection{Confirmation Experiments}

Further to continuation of the validity of the obtained model Eq. (21) for the radial vibration amplitude at the synchronous frequency component, confirmation experiments were conducted using Taguchi's design using the factors and their levels
Table 6. Parameters and values.

\begin{tabular}{|l|l|l|}
\hline Rotor & Disc & Bearing \\
\hline$d_{s}=25$ & $M_{\text {Disc }}=0.5$ & $C_{r}=11$ \\
$L_{s}=390$ & $\rho_{\text {Disc }}=7800$ & $D_{p}=36$ \\
$\rho_{s}=7800$ & $E_{D i s c}=200 \times 10^{9}$ & $v=96$ \\
$m_{s}=1.5$ & - & $D_{r}=6.75$ \\
$E_{s}=200 \times 10^{9}$ & - & $Z=10$ \\
- & - & $K_{c}=274870.7$ \\
\hline
\end{tabular}

Table 7. Confirmation experiments.

\begin{tabular}{||l|l|l|l|l|l|l|l||}
\hline Expt. & $\mathrm{M}_{\mathrm{u}}$ & $\mathrm{N}$ & $\mathrm{e}_{\mathrm{r}}$ & $\mathrm{W}$ & $y_{i}$-Expt. & $\begin{array}{l}y_{i} \text {-Model } \\
(\text { Eq. 21) }\end{array}$ & $\begin{array}{l}y_{i} \text {-Regression } \\
(\text { Eq. 22) }\end{array}$ \\
\hline 1 & 15 & 1020 & 60 & 1000 & 15.4 & 15.29 & 17.58 \\
2 & 15 & 2040 & 70 & 2000 & 39.2 & 38.47 & 42.16 \\
3 & 15 & 3060 & 80 & 3000 & 74.5 & 74.30 & 84.65 \\
4 & 20 & 1020 & 70 & 3000 & 45.6 & 44.30 & 49.37 \\
5 & 20 & 2040 & 80 & 1000 & 50.4 & 49.64 & 52.01 \\
6 & 20 & 3060 & 60 & 2000 & 35.8 & 34.17 & 39.14 \\
7 & 25 & 1020 & 80 & 2000 & 62.1 & 61.95 & 65.05 \\
8 & 25 & 2040 & 60 & 3000 & 41.5 & 41.23 & 47.49 \\
9 & 25 & 3060 & 70 & 1000 & 46.2 & 44.80 & 48.39 \\
\hline
\end{tabular}

as listed in Tab. 3. Taguchi design helps in reduction of number of experiments by making use of the orthogonal array. ${ }^{28,29}$ The rotor-disc-bearing parameters used for the obtaining the synchronous vibration amplitude using Eq. (21) are taken from Tab. 6.

Table ?? gives $\mathrm{L}_{9}$ orthogonal array which also list the results of the confirmation experiments and a comparison between the model Eq. (21) and the regression Eq. (22).

For the trials listed in Table ??, the experimental response plots are obtained using the multichannel vibration analyzer by conducting experiments on the set up shown in Fig. 1.

Figure 2 shows response plot for the experiment 1 which was obtained at a rotor speed of $1020 \mathrm{rpm}$.

As expected, first harmonic of the rotor speed frequency has shown a principal peak due to seeded unbalance with an rms amplitude value of $15.4 \mu \mathrm{m}$. The amplitude values predicted by the proposed model Eq. (21) and the regression Eq. (22) are $15.29 \mu \mathrm{m}$ and $17.58 \mu \mathrm{m}$ respectively. The other peaks seen in Fig. 2 are the harmonics of the rotor speed frequency which are because of the unbalance on the rotor. Figure 3 shows the response plot for the confirmation experiment 2 which was obtained at a rotor speed of $2040 \mathrm{rpm}$.

The principal peak observed from the spectrum is at the first harmonic of the shaft speed frequency of $34 \mathrm{~Hz}$ having rms amplitude of $39.2 \mu \mathrm{m}$. The model Eq. (21) and the regression Eq. (22) also predicted the values of the vibration amplitude of $38.47 \mu \mathrm{m}$ and $42.16 \mu \mathrm{m}$ respectively which are closer to the experimental data.

Figure 4 shows the frequency spectrum for the third confirmation experiment conducted at $3060 \mathrm{rpm}$ rotor speed.

A significant peak of $74.5 \mu \mathrm{m}$ amplitude is noticed at the $51 \mathrm{~Hz}$ frequency which corresponds to the first harmonic of the rotor speed frequency. The model Eq. (21) predicts the vibration amplitude of $74.30 \mu \mathrm{m}$ and the regression Eq. (22) has predicted a peak of $84.65 \mu \mathrm{m}$ which are nearly matching with the experimentally obtained peak. Similarly for the other experiments similar results are noticed as seen from the experimental spectrums shown in Figures 5-10 and the comparison of the vibration amplitudes as summarized in Table ??.

Figure 11 gives the comparison between the rms vibration amplitude at synchronous frequency component obtained us- 


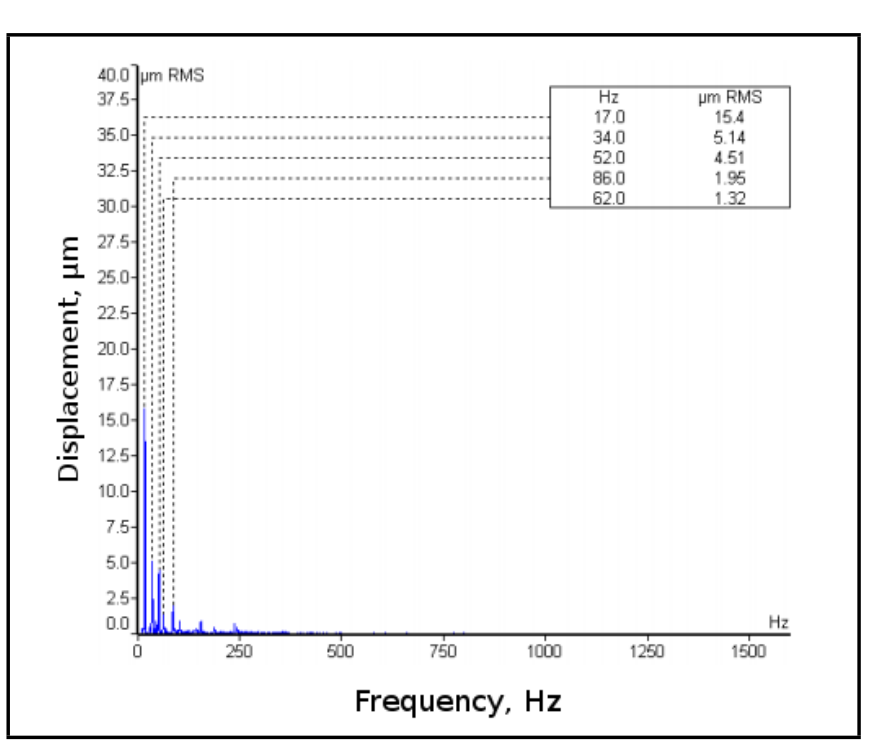

Figure 2. Response Plot for experiment 1.

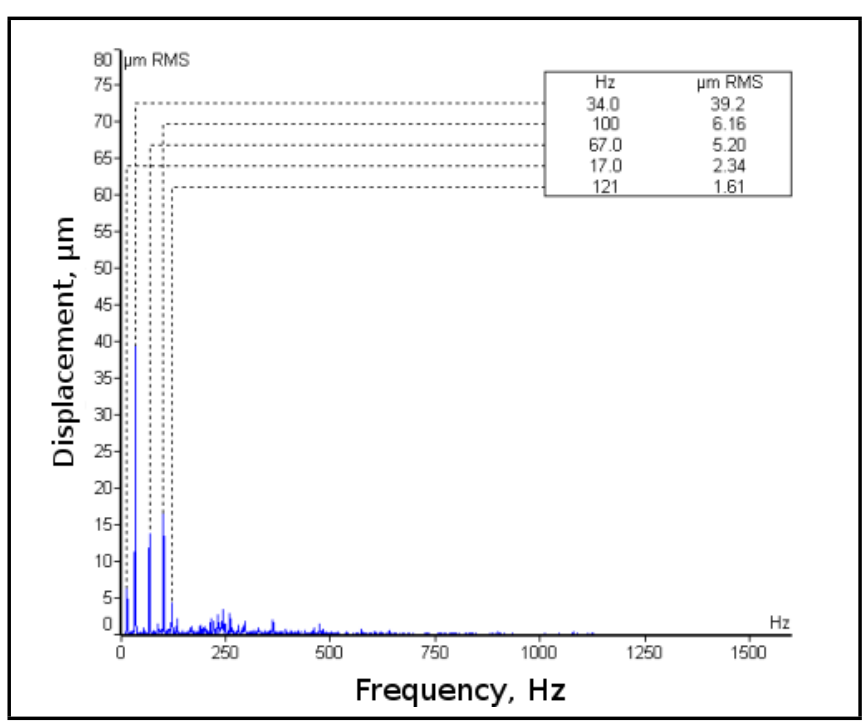

Figure 3. Response Plot for experiment 2.

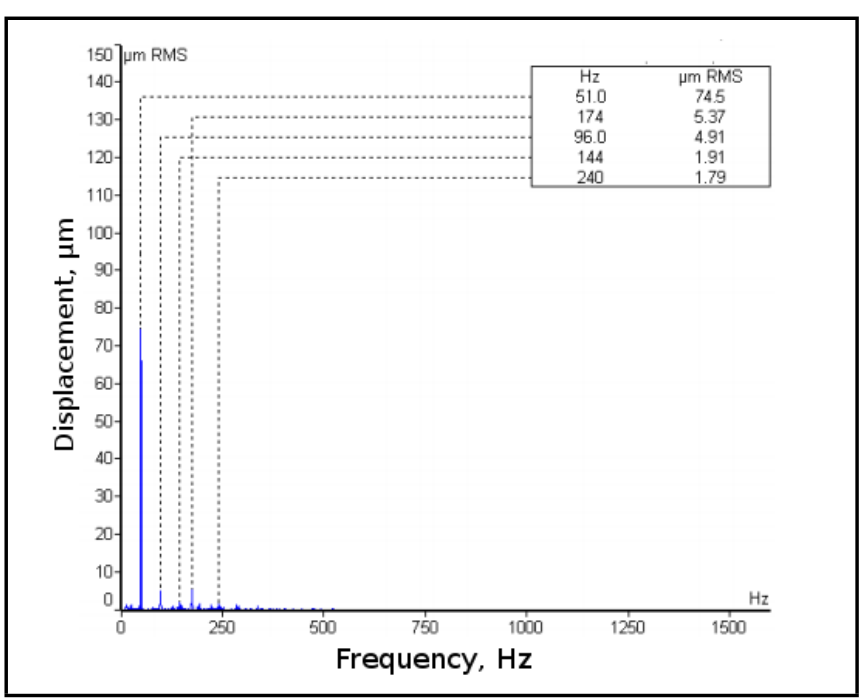

Figure 4. Response Plot for experiment 3.

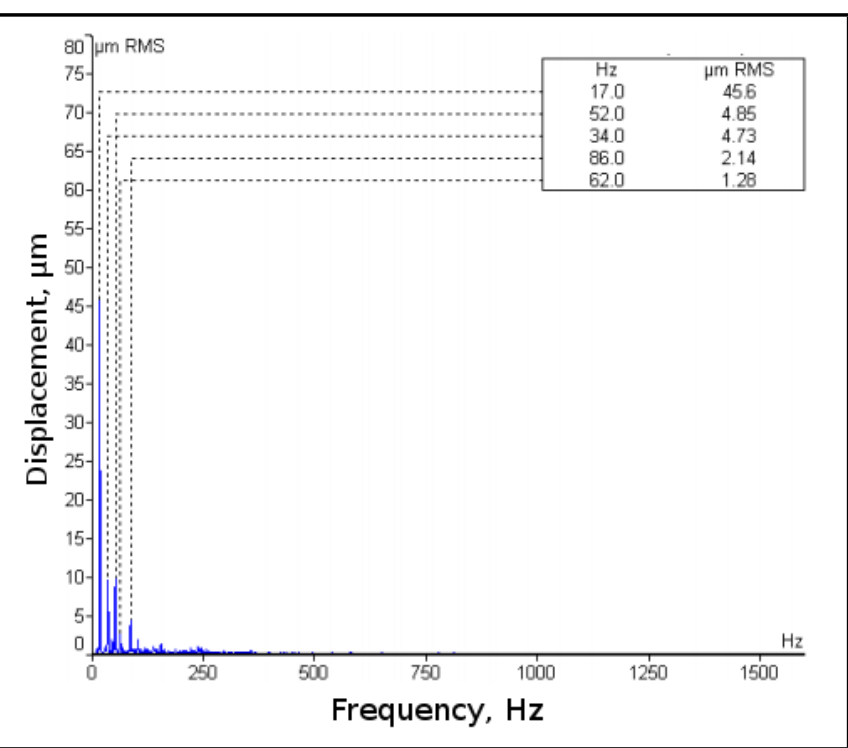

Figure 5. Response Plot for experiment 4.

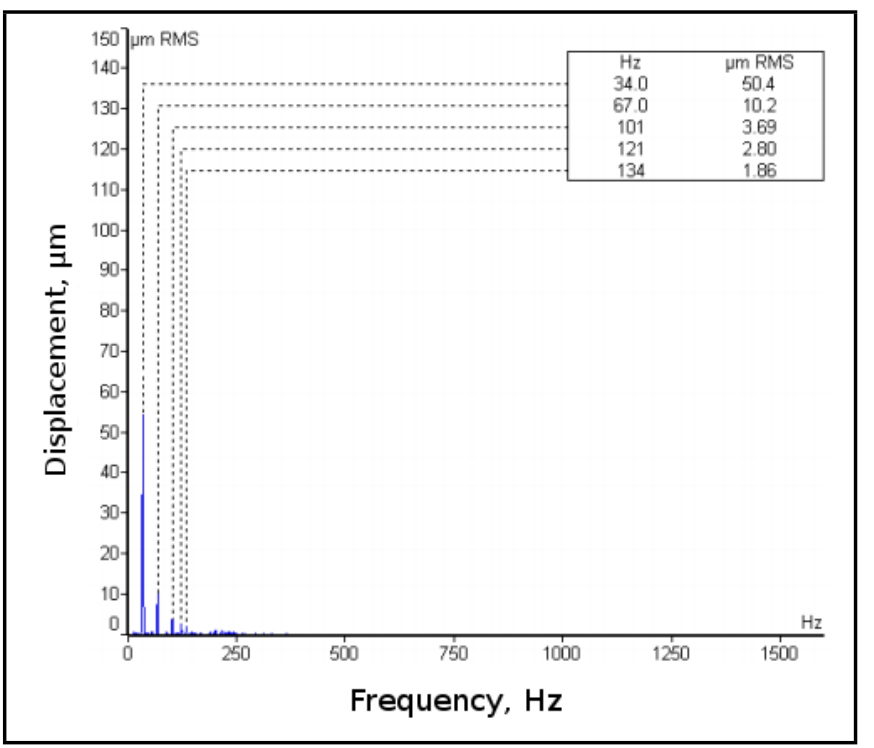

Figure 6. Response Plot for experiment 5.

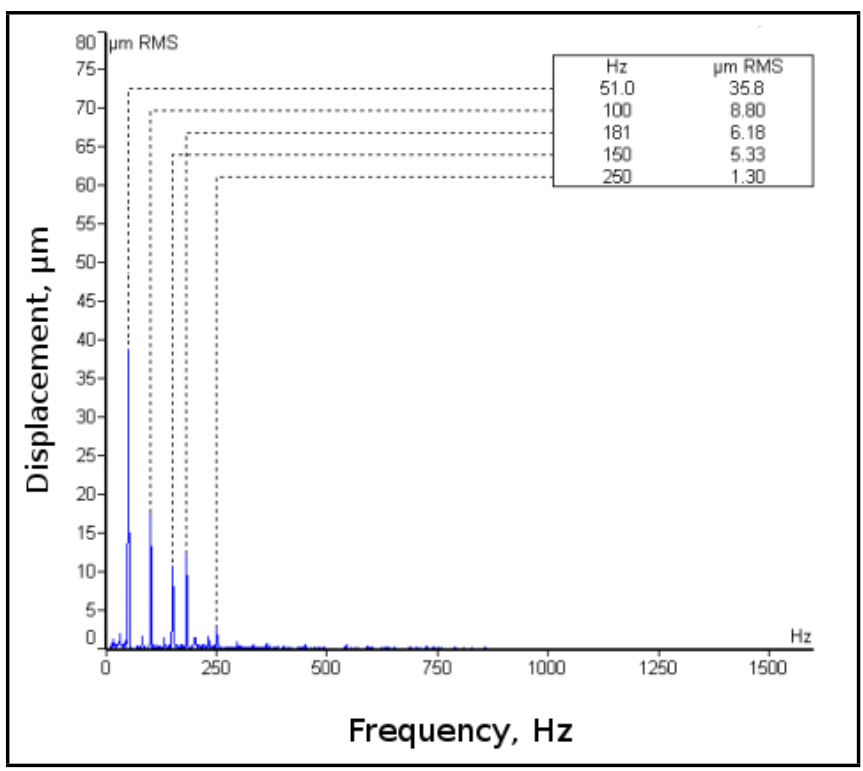

Figure 7. Response Plot for experiment 6. 


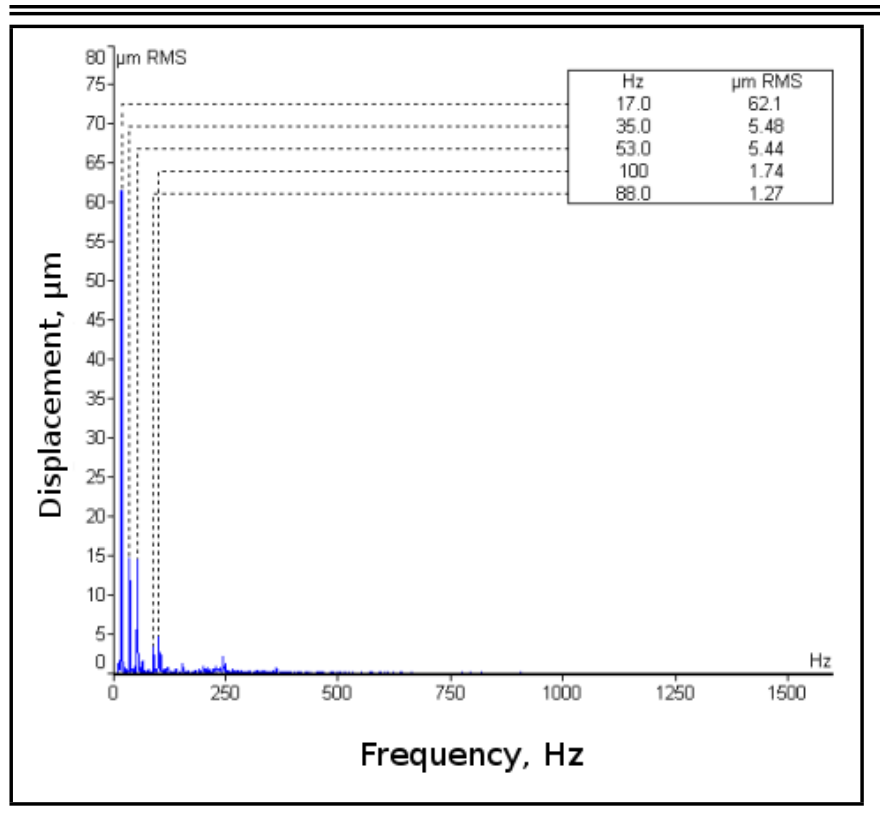

Figure 8. Response Plot for experiment 7.

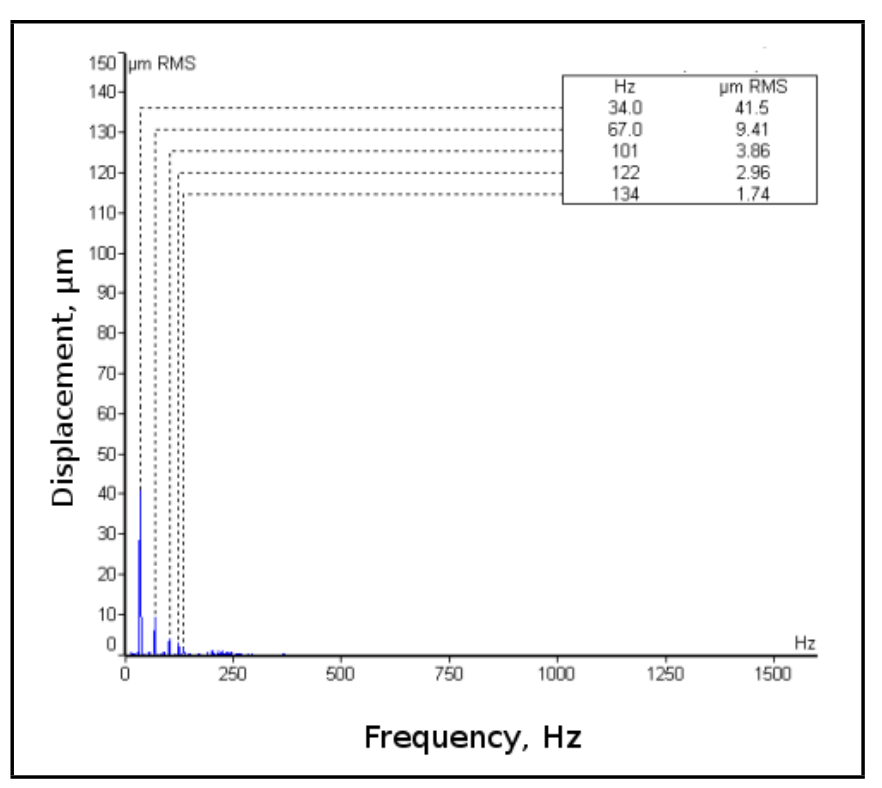

Figure 9. Response Plot for experiment 8.

ing mathematical model Eq. (21), regression Eq. (22) and the experimental data, a fair amount of closeness can be seen.

\subsection{Effect of Rotor Speed}

Figure 12 shows the effect of rotor speed on the radial vibration amplitude at synchronous frequency. Here, the non-dimensional vibration amplitude $\left(\pi_{y}\right)$ is plotted against thenon-dimensional rotor speed term $\left(\pi_{1}\right)$. It is evident that the vibration amplitude increases with increase in rotor speed has significant effect at $3060 \mathrm{rpm}$ as compared to $1020 \mathrm{rpm}$ and suffices the theoretical development of the $\pi_{1}$ term.

\subsection{Effect of Mass Eccentricity Radius}

Figure 13 shows the effect of eccentricity radius on the radial vibration amplitude at synchronous speed frequency. Here, the non-dimensional vibration amplitude $\left(\pi_{y}\right)$ is plotted against thenon-dimensional eccentricity radius term $\left(\pi_{2}\right)$. As seen from the figure, with increase in the mass eccentricity

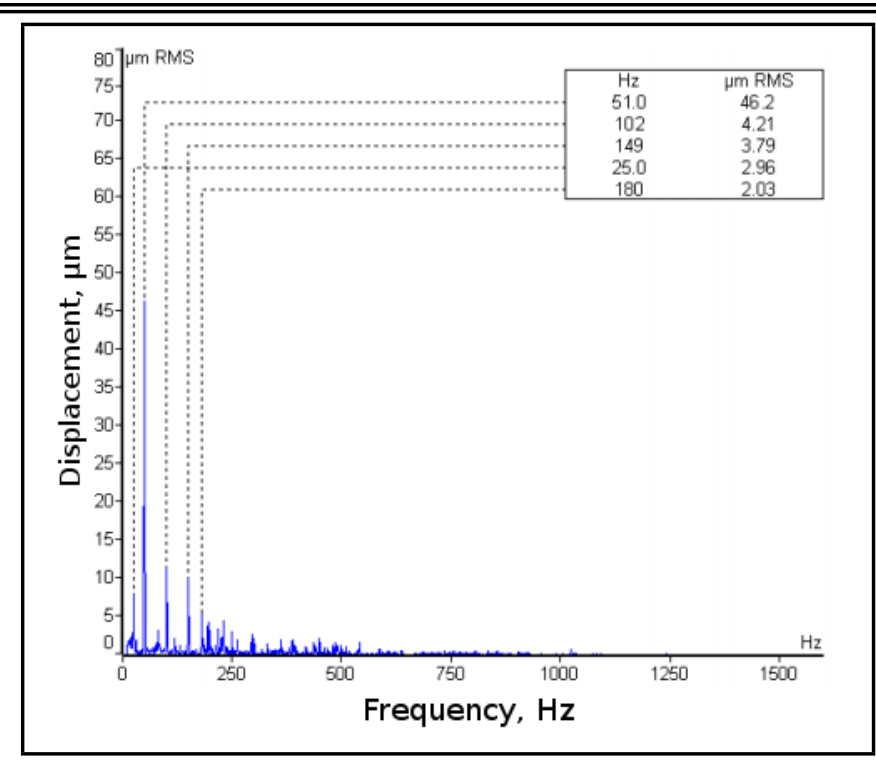

Figure 10. Response Plot for experiment 9.

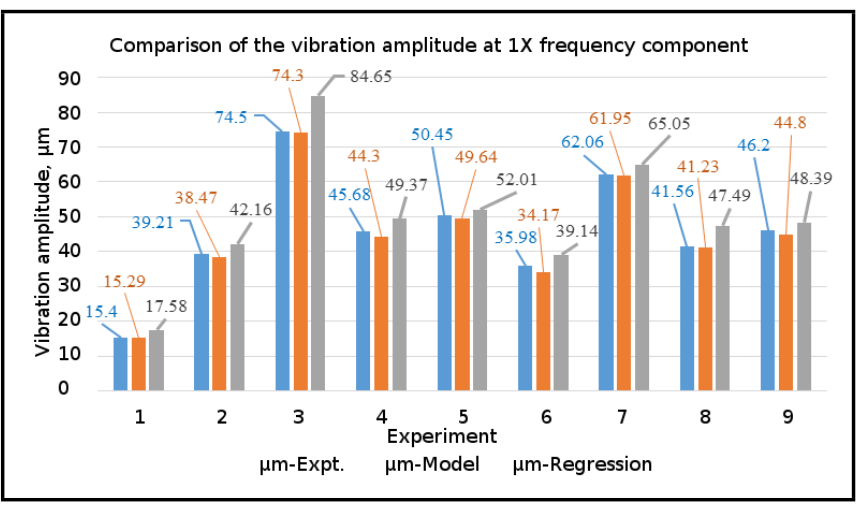

Figure 11. Comparison of the vibration amplitude.

radius, the amplitude found to be increasing and justifies the theoretical development of $\pi_{2}$ term.

\subsection{Effect of Mass Unbalance}

Figure 14 shows the effect of mass unbalance on the radial vibration amplitude at synchronous speed frequency. Here, the non-dimensional vibration amplitude $\left(\pi_{y}\right)$ is plotted against thenon-dimensional mass unbalance $\operatorname{term}\left(\pi_{5}\right)$.The radial vibration amplitude at synchronous frequency component was found to be increasing with increase in mass unbalance from 15 to $25 \mathrm{gm}$. justifies the theoretical development of $\pi_{5}$ term.

\section{CONCLUSION}

In the present investigation, a numerical model is developed for prediction of vibration displacement amplitude of synchronous frequency component of an unbalanced rotor-bearing system following rigid rotor approach. The numerical results have validated for different experimental conditions with experiments conducted in laboratory test rig. In this study the use of design of experiments implementing the response surface method and the Taguchi design is made for exploring simultaneous effect of the variables such as rotor unbalance, speed, eccentricity radius, radial load etc. with three levels on the vibration displacement amplitude. All these experiments are designed to consider 2-way interaction among the variables and 


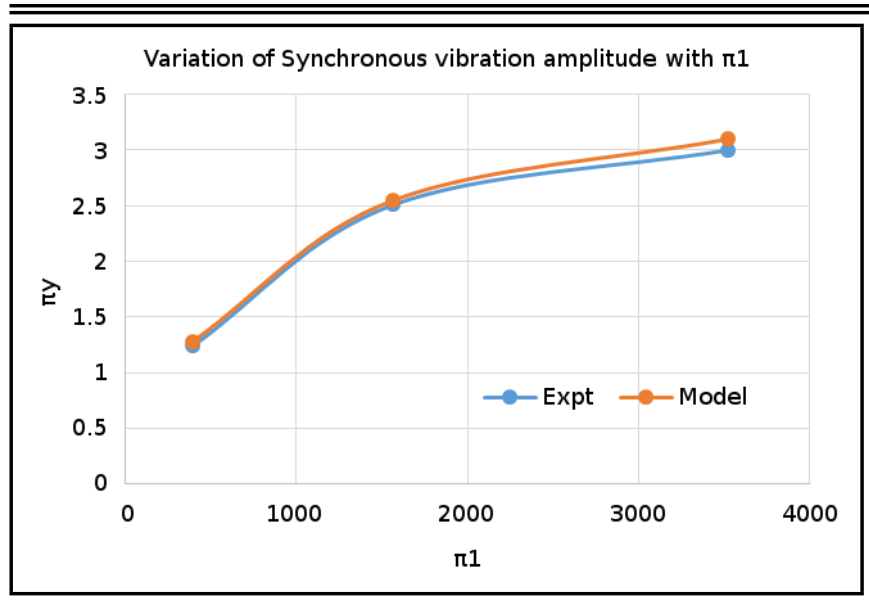

Figure 12. Variation of non-dimensional vibration amplitude vs nondimensional rotor speed [at $1020 \mathrm{rpm}, 2040 \mathrm{rpm}, 3060 \mathrm{rpm}$ ].

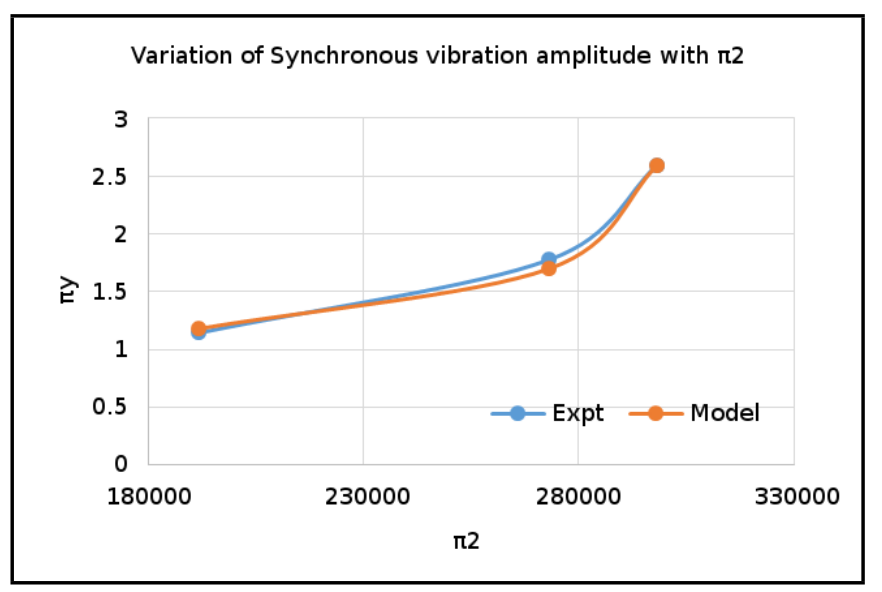

Figure 13. Variation of non-dimensional vibration amplitude vs nondimensional eccentricity radius [at $60 \mathrm{~mm}, 70 \mathrm{~mm}, 80 \mathrm{~mm}$ ].

also the main effects of the individual variables as mentioned. From the obtained results, the following points can be deduced,

i. The synchronous vibration displacement amplitude is found to be dependent on the level of unbalance, rotor speed, eccentricity radius and the radial load.

ii. The synchronous speed frequency shows a principal peak due to seeded unbalance in all the experimental trials with the presence of the harmonics of the speed frequency (Figures 2-10).

iii. With increase in the non-dimensional rotor speed, the non-dimensional displacement amplitude at synchronous speed frequency is found to be increasing and has significant effect at $3060 \mathrm{rpm}$ as compared to $1020 \mathrm{rpm}$ (Figure 12).

iv. It is evident that the non-dimensional vibration displacement amplitude at synchronous frequency component increases with increase in the non-dimensional eccentricity radius term and the non-dimensional unbalance terms in that the eccentricity radius has considerable effect on the amplitude (Figure 13, 14).

v. To avoid and control the unstable rotor response, an electromagnetic actuator or active magnetic bearings along with the suitable PID control may be placed on the shaft at a suitable position, and the obtained displacement of a

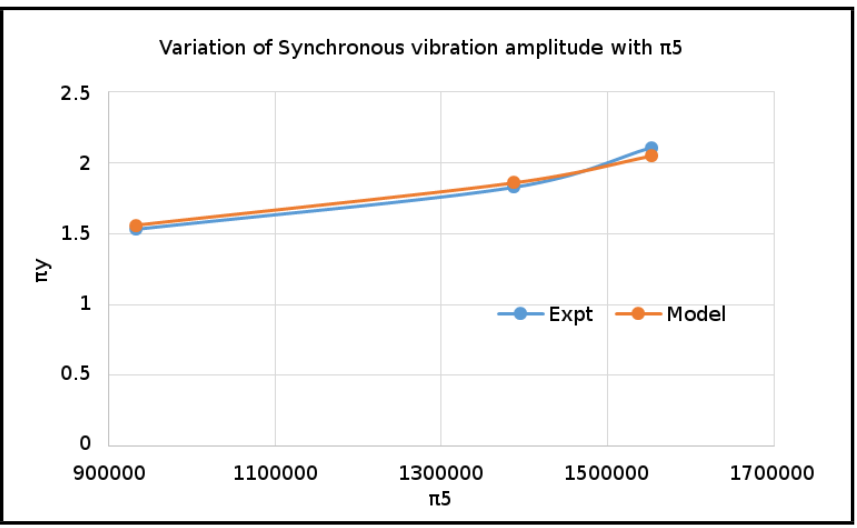

Figure 14. Variation of non-dimensional vibration amplitude vs nondimensional mass unbalance [at $15 \mathrm{gm}, 20 \mathrm{gm}, 25 \mathrm{gm}$ ].

point of the rotor may be fed to the controller. Then the stiffness of the shaft may be adjusted to keep the zones of instability away from the excitation zone caused due to unbalance.

vi. The different mountings on the shaft used in rotating machineries such as turbine, flywheel, gears etc. can be modelled as disk as per the methodology presented in this paper. The geometrical, material parameters associated with these components needs to be in corporate in the theoretical model. Then during the trial experimental work, the effect of the amount of the increase in the synchronous vibration amplitude due to changes in position and magnitude of unbalance on different disks needs to be obtained by selecting the appropriate balancing planes. The suitable trial mass will be selected and state of the art methods for the correction of the unbalance can be implemented.

\section{PURVIEW}

The proposed technique may also be utilized for the online or real time monitoring of the rotor instability and unbalance estimation. The obtained synchronous vibration displacement may be fed to the suitable machine learning algorithm consisting of the neural networks, genetic algorithm, neuro-fuzzy system, or support vector machine classifier to predict the real time machine working condition. Future research will deal with this aspect.

\section{REFERENCES}

1 Sujatha, C., Vibration and Acoustics-Measurement and Signal Analysis, Tata Mcgraw Hill Education Private Limited, New Delhi, 242-290, ISBN: 9780070148789, (2010).

2 Wang, A., Yao, W., He, K., Meng, G., Cheng, X., and Yang, J., Analytical modelling and numerical experiment for simultaneous identification of unbalance and rolling-bearing coefficients of the continuous single-disc and single-span rotor-bearing system with Rayleigh beam model, Mechanical Systems and Signal Processing, 116, 322-346, (2019). https://dx.doi.org/10.1016/j.ymssp.2018.06.039

3 Liu, Y., Zhang, M., Sun, C., Hu, M., Chen, D., Liu, Z., and Tan, J., A method to minimize stage-by-stage initial unbalance in the aero engine assembly of multistage rotors, Journal of Aerospace Science and Technology, 85, 270276, (2019). https://dx.doi.org/10.1016/j.ast.2018.12.007 
4 Shrivastava, A., and Mohanty, A.R., Identification of unbalance in a rotor system using a joint input-state estimation technique, Journal of Sound and Vibration, (2019). https://dx.doi.org/10.1016/j.jsv.2018.11.019

5 Ambur, R., and Rinderknecht, S., Unbalance detection in rotor systems with active bearings using self-sensing piezoelectric actuators, Mechanical Systems and Signal Processing, 102, 72-86, (2018). https://dx.doi.org/10.1016/j.ymssp.2017.09.006

6 Al-Shudeifat, M.A., Hosani, H.A., Saeed, A.S., and Balawi, S., Effect of Unbalance Force Vector Orientation on the Whirl Response of Cracked Rotors, Journal of Vibration and Acoustics, 141, 021001-1-10, (2019). https://dx.doi.org/10.1115/1.4041462

7 Cao, H., He, D., Xi, S., and Chen, X., Vibration signal correction of unbalanced rotor due to angular speed fluctuation, Mechanical Systems and Signal Processing, 107, 202-220, (2018). https://dx.doi.org/10.1016/j.ymssp.2018.01.030

8 Sanches, F.D., and Pederiva, R., Simultaneous identification of unbalance and shaft bow in a two-disk rotor based on correlation analysis and the SEREP model order reduction method, Journal of Sound and Vibration, 433, 230-247, (2018). https://dx.doi.org/10.1016/j.jsv.2018.07.021

9 Shrivastava, A., and Mohanty, A.R., Estimation of single plane unbalance parameters of arotor-bearing system using Kalman filtering based force estimation technique, Journal of Sound and Vibration, 418, 184-199, (2018). https://dx.doi.org/10.1016/j.jsv.2017.11.020

10 Wang, N., and Jiang, D., Vibration response characteristics of a dual-rotor with unbalance-misalignment coupling faults: Theoretical analysis and experimental study, Journal of Mechanism and Machine Theory, (2018). https://dx.doi.org/10.1016/j.mechmachtheory.2018.03.009

11 Yao, J., Liu, L., Yang, F., Scarpa, F., and Gao, J., Identification and optimization of unbalance parameters in rotorbearing systems, Journal of Sound and Vibration, 431, 5469, (2018). https://dx.doi.org/10.1016/j.jsv.2018.05.050

12 Bartkowiak, R., Controlled synchronization at the existence limit for an excited unbalanced rotor, International Journal of Non-Linear Mechanics, 91, 95-102, (2017). https://dx.doi.org/10.1016/j.ijnonlinmec.2017.02.012

13 Fonseca, C.A., Santos, I.F. and Weber, H.I., Influence of unbalance levels on nonlinear dynamics of a rotor-backup rolling bearing system, Journal of Sound and Vibration, 394, 482-496, (2017). https://dx.doi.org/10.1016/j.jsv.2017.01.020

14 Wang, A., Cheng., X., Meng, G., Xia, Y., Wo, L., and Wang, Z., Dynamic analysis and numerical experiments for balancing of the continuous single-disc and single-span rotor-bearing system, Mechanical Systems and Signal Processing, 86, 151-176, (2017). https://dx.doi.org/10.1016/j.ymssp.2016.09.034

15 Shamsah, S.M.I., Sinha, J.K., and Mandal, P., Estimating rotor unbalance from a single run-up and using reduced sensors, Measurement, 136, 11-24, (2018). https://dx.doi.org/10.1016/j.measurement.2018.11.044
16 Yadav, H.K., Upadhyay, H.K., and Harsha, S.P., Study of effect of unbalanced forces for high speed rotor, Procedia Engineering, 64, 593-602, (2013). https://dx.doi.org/10.1016/j.proeng.2013.09.134

17 Ocampo, J. C., Wing, E.S.G., Moroyoqui, F.J.R, Pliego, A.A., Ortega, A.B., and Mayén, J., A novel methodology for the angular position identification of the unbalance force on asymmetric rotors by response polar plot analysis, Mechanical Systems and Signal Processing, 95, 172-186, (2017). https://dx.doi.org/10.1016/j.ymssp.2017.03.028

18 Bartkowiak, R., Controlled synchronization at the existence limit for an excited unbalanced rotor, International Journal of Non-Linear Mechanics, 91, 95-102, (2017). https://dx.doi.org/10.1016/j.ijnonlinmec.2017.02.012

19 Wen, B., Wang, M., Zhou, X., Ren, H. and Han, Q., Multi-harmonic motions of bearing cage affected by rotor unbalance, Journal of Mechanical Engineering Science, https://dx.doi.org/10.1177/0954406217722380

20 M. Arias-Montiel, F. Beltrán-Carbajal, G. Silva-Navarro, On-line algebraic identification of eccentricity parameters in activerotor-bearing systems, International Journal of Mechanical Sciences, 85, 152-159, (2014). https://dx.doi.org/10.1016/j.ijmecsci.2014.05.027

21 Gibbings, J.C., Dimensional Analysis, Springer-Verlag London Ltd. ISBN: 978-1-84996-317-6, (2011). https://dx.doi.org/10.1007/978-1-84996-317-6

22 I. M. Jamadar and D. P. Vakharia, A New Damage Diagnostic Aoach for Deep Groove Ball Bearings Having Localized Surface Defects in the Raceways, ASME, Journal of Tribology, 139, 061103-1-10, (2017). https://dx.doi.org/10.1115/1.4036630

23 I. M. Jamadar, S. A. I. Bellary, R. A. Kanai and A. A. Alrobaian, Model-Based Condition Monitoring for the Detection of Failure of a Ball Bearing in a Centrifugal Pump, Journal of Failure Analysis and Prevention, 19, 1556-1568, (2019). https://dx.doi.org/10.1007/s11668-019-00792-x

24 Thomas, S., Aied Dimensional Analysis and Modeling, Elsevier Inc., Publication, 163-228, ISBN: 9780123706201, (2007).

25 Raymond, H. M., Douglas, C. M.,Christine, M. A.C., Response surface methodology, John Wiley \& Sons, Inc., Publication, ISBN: 978-1-118-91601-8, (2009).

26 Rudra Pratap, Getting Started with MATLAB: A Quick Introduction for Scientists \& Engineers, Oxford University Press, South Asia Edition, ISBN:9780190091972, (2010).

27 Thomas, P. R., Modern Experimental Design, John Wiley \& Sons, Inc., Publication, ISBN:9780471210771, (2007). https://dx.doi.org/10.1002/0470074353

28 Montgomery, D.C., Design and analysis of experiments, 7th ed., Willey India, ISBN: 978-1-119-49244-3, (2009).

29 Roy, R. K., Design of Experiments using Taguchi Aoach, John Wiley and Sons, Inc. New York, USA, ISBN: 978-0471-36101-5, (2001). 